\title{
Gender and Education
}

\author{
Olof Steinthorsdottir and Veronique Lizan
}

\section{Report}

While mathematics are universal, it appears that delicate process in the classroom, but not only there, lead boys and girls to perceive things differently. And from this perception at school depends the future of the jobs. If the teacher, male or female, is conscious of this, what can he/she do to provide to each pupil or student, boy or girl, the opportunity of understanding, participating and finally appreciating mathematics at best?

The subject is not new: it merges explicitly at ICME3 in Karlsruhe (Germany) in 1976. «[...] Moreover, it is recommended that the theme 'Women ans Mathematics' be an explicit theme of ICME 1980.»: this ends the third and last resolution of the Congress. This recommandation became realised at ICME4 in Berkeley in 1980 and goes on since.

From the proposals received for ICME12 from all over the world, the reflection at Topic Study Group «Gender and Education» was organised along four themes: gender issues in research and learning environmental; student's achievement, assessment and classroom activities; self-efficacy and attitudes; gendered views of mathematics.

Organizers Co-chairs: Olof Steinthorsdottir (USA), Veronique Lizan (France); Team Members: Collen Vale (Australia), Laura Martigon (Germany), Sun Hee Kim (Korea); Liaison IPC Member: Cheryl Praeger (Australia).

O. Steinthorsdottir $(\bowtie)$

University of Northern Iowa, Cedar Falls, USA

e-mail: olly.steintho@uni.edu

V. Lizan

Institut de Mathématiques de Toulouse, Toulouse, France

e-mail: veronique.lizan@math.uni-toulouse.fr

(C) The Author(s) 2015 
The subject deals with the notion of «gender», that has merged in sociology studies during $70 \mathrm{~s}$ and it took time to work out a definition since gender doesn't reduce to sex. The term appeared in ICMI history first in 1992; it was introduced at ICME7 in Québec by IOWME.

Indeed, gender and mathematics is at the crossing of different subjects (sociology, psychology, biology or anthropology for example) what is not surprising since teaching mathematics to pupils or students generates interactions between the teacher and the classroom but also between classroom members. So it is at the same time a complex but also a completely natural subject, so natural that it can sound unrelevant.

\section{What Do We Learn on «Gender and Mathematics» at ICME12?}

The aim of the first session was to establish some basis: precisely define vocabulary, revisit the term « gender » for maths classrooms and develop a methodology to study what happens in a math class when considered from a gendered viewpoint. Indeed, crossing gender with mathematics stakes very delicate process and it is essential to circumscribe the studied objects and the way they'll be studied in any research on the subject.

The second session pointed that different social parameters impact pupils achievement to international tests or national selection process, especially those that concern family background. The type of tests or criteria of selection can also introduce unsuspected bias into selection process. Gender interfers with mathematics achievement not only in the classroom but everywhere from the moment there are human relationships, and more acutely when mathematics are assigned a role of selection, quite a social selection role.

The third session enlighted how important is the way of teaching to catch the interest of pupils - the girls of the study appreciate to be responsibilized and active - and also how important is the involvement of parents for maths studies or topics in pupils' interest for maths and their success, especially concerning girls. In maths teaching process, the content is important of course, but the manner also is of importance as well as the environment knowledge to try to equally imply most if not all pupils or students of a classroom and make them feel concerned by the maths class. Reading ability of course is also a technical factor of success for students in mathematics through their self-assessment - the best they read and the more acurately self-assessment is perceived to perform-Self-efficacy that boys and girls don't live in he same way especially during problem-solving tasks is also a parameter of importance in mathematical activity environment. It is precisely when the maths activity perturbates the pupil, the pupil's security in some way (difficult question or open problem for example) that some aspects of each pupil's personality built since childhood stake. In that sense maths activity actively participates in the personal construction of each pupil. 
The fourth session pointed that children at pre-school are already submitted to gendered stereotypes during mathematics activities, and also that gender and mathematics are related to cultural parameters even if statistics show differences between boys and girls achievements in the same sense everywhere: mathematics are abstract and universal but the question is the same everywhere independantly of cultures.

\section{Perspectives for the Future}

Different gender activities were disseminated in ICME12 program and one could concoct a quite full time «Gender and mathematics» program during the congress : part of Gilah Leder's talk since gender is one of her interests; an overview «Gender and Mathematics education (revisited)»; 2 IOWME (International Organization of Women in Mathematical Education) meetings; a Girls' day organised by KWMS (Korean Women in Mathematical Sciences) and WISET (Korea Advanced Institute of Women in Science, Engineering and Technology); and of course the topic study group «Gender and Mathematics» and its four sessions. The Girls' day mentoring activity was of special interest because it involved about 110 girls and also mentors, women maths researchers or scientific engineers; it was related to the WISET stand at the Mathematical Carnival and also to activities especially for girls. Analogous days also exist in Australia, France or USA for example, and they constitute a first step to an active treatment of gender and mathematics, or more generally science, topic.

Anyway the public at the topic study group was essentially constituted by people already conscious that mathematical activity at school has not the same social meaning or psychological impact for boys as for girls. But, are all of us that teach mathematics to both female and male conscious (or convinced?) that both publics don't deal with mathematics in the same way? And how to make a math course equally attractive for boys and for girls?

Of course, ICME takes the subject of gender and mathematics into account since its very beginning. Anyway it is not a timeworn leitmotiv since the corpus on gender and mathematical education constitutes along years. On the contrary, it is necessary to wake up that the question is of importance and to become aware that it is closely related to the future of mathematics and science that lack of students for both research, engineering and technology.

Scientists are already active on the subject (Cf. Girls' day and also the work of the devoted associations). When will teachers be systematically trained to consider their pupils also as boys and girls and then when will teachers take into account in their practice gender angle to tackle their classes? And what contents for training teachers on the subject? Perhaps subjects at a plenary talk in a future ICME.

Open Access This chapter is distributed under the terms of the Creative Commons Attribution Noncommercial License, which permits any noncommercial use, distribution, and reproduction in any medium, provided the original author(s) and source are credited. 